www.jmscr.igmpublication.org

Impact Factor 5.84

Index Copernicus Value: 71.58

ISSN (e)-2347-176x ISSN (p) 2455-0450

crossref DOI: _https://dx.doi.org/10.18535/jmscr/v5i11.206

Journal Of Medical Science And Clinical Research

IGM Publication

An Official Publication of IGM Publication

\title{
A prospective study comparing visual outcomes and complications of Anterior Chamber Intra ocular lenses versus Scleral fixated Intra ocular lenses in various complicated cataract surgeries
}

\author{
Authors \\ Anand Verma M.S. ${ }^{1}$, Pratibha Kaushal ${ }^{2}$ \\ ${ }^{1}$ Associate Professor, Dept of Ophthalmology, Rama Medical College and Hospital, Hapur U.P., (India) \\ ${ }^{2}$ Ex Senior Resident Dept of Anaesthesiology, School of Medical Sciences \& Research, Sharda University, \\ Greater Noida \\ Corresponding Author \\ Dr Anand Verma MS \\ Associate Professor, Rama Medical College and Hospital, Hapur U.P., (India) \\ Address: Tower No- 6 , Flat No - A/3- 601, Silver City 2, Sector Pi - 2, Greater Noida-201308 \\ Email: dr_anand74verma@ rediffmail.com
}

\begin{abstract}
Purpose: To compare visual outcome and complications of Anterior chamber Intra ocular lens implantation versus Scleral fixated Intra ocular lens implantation in various complicated cataract surgeries.

Material and Methods: A total of 36 patients of complicated cataract and Aphakia were included in this study. They were randomly divided into two group. Eighteen cases underwent anterior chamber IOL (AC$I O L)$ implantation other eighteen cases underwent sclera fixated IOL (SF-IOL) implantation. Visual outcome and complications in both the cases were analyzed.

Result: In our study we found that the best corrected visual acuity was slightly higher and complication rate was lower in SF-IOL implantation group than AC-IOL implantation group and SF-IOL implantation is better alternative to AC-IOL in aphakia and complicated cataract surgeries where capsular support is weak.

Keywords: Anterior Chamber IOL, Scleral Fixated IOL, Intra Ocular Lens, Complicated cataract, Subluxated cataract, Aphakia.
\end{abstract}

\section{Introduction}

Visual rehabilitation with intra ocular lens (IOL) is an ideal and better option in aphakic eyes as compared to correction with aphakic spectacle and contact lens. Available option for managing cases when there is posterior capsule rupture and cases when there is lack of zonular capsule support include an anterior chamber (AC) IOL, sclera fixated IOL and iris fixated PC IOL. It has been postulated that AC IOLs are associated with many complications like glaucoma, hyphema, uveitis, cystoids macular oedema and corneal decompensation. The SF IOL is other alternative but it has its own associated limitations. SF IOL can be used in both adults and children. SF IOL is associated with IOL tilt and decentration and other complications. Still considerable controversy remains over the relative efficacy and safety of 
different implantation approaches when capsular support is absent or weak.

\section{Materials \& Methods}

This is prospective study for which ethics committee approval was obtained. The patients were recruited from outpatient department of Ophthalmology of Rama Medical College and Hospital, Hapur and admitted in Rama Medical College and Hospital, Hapur. A total of 36 patients of complicated cataract and old aphakia were included in this study. All patients gave full informed consent for surgery. They were randomly divided into two groups.

Group A: Eighteen patients who underwent Anterior chamber IOL either as primary or secondary IOL implantation.

Group B: Eighteen patients who underwent Scleral Fixated IOL either as primary or secondary IOL implantation.

Inclusion Criteria: Mature and immature Senile cataracts in which posterior capsular rent occurred, old aphakia patients whose best corrected visual acuity was good, traumatic and subluxated cataracts

Exclusion Criteria: Included iritis, uveitis, glaucoma, amblyopia, macular scar and patients with poor vision other than cataract.

All selected patients underwent full ophthalmic and systemic examination. Preoperative vision, applanation tonometery, slit lamp examination, corneal thickness, specular microscopy, gonioscopy and fundus examination was done in all patients.

Surgical Technique: Complete aseptic precaution was taken and peribulbar anaesthesia was given in every case.

\section{Group A: AC IOL Implantation}

Entirely a new wound is constructed superiorly under the lid. Peritomy was done. A $6 \mathrm{~mm}$ sclerocorneal tunnel $1 \mathrm{~mm}$ posterior to limbus is constructed. At 3'0 clock position a side port is made through which intracameral pilocarpine is injected into anterior chamber to induce miosis. Entry is made through main superior wound and bimanual automated vitrectomy was performed. Viscoelastic substance hydroxypropyl methylcellulose $2 \%$ was injected into anterior chamber and a peripheral irodotomy was created with the help of automated vitrector away from the haptics of IOL which had to implanted. AC IOL with A constant 114.9 of calculated power in case of secondary AC IOL implantation or of power less 3 diopter than PC IOL power in case of primary AC IOL implantation were selected. Viscoelastic substance (Hydroxypropyl methylcellulose 2\%) is injected and AC IOL was implanted using Kelman-McPherson forceps and Kuglen hook. Hydroxypropyl methylcellulose substance was aspirated and wound was closed by putting two 10-0 nylon suture. The peritomy was closed using buried 8-0 Vicryl sutures.

Group B : SF IOL Implantation

All the procedures like peritomy, superior sclerocorneal tunnel construction, vitrectomy and peripheral iridotomy were same as in group A. Besides these, two scleral pockets were made 180 degree apart (avoiding 3 and 9 o clock position). Scleral fixation suture prolene 10-0 double arm with straight needle passed from one sclera pocket to opposite sclera pocket. Suture was pulled out with the help of sinsky hook through superior sclerocorneal tunnel and suture was cut. Cut end of suture were tied with the holes of haptic of sclera fixated intra ocular lens. Other end of sutures was pulled and IOL was inserted in posterior chamber. Straight needle of the suture was then passed through sclera and tied. Scleral pockets was sutured with 10-0 nylon. Conjuctival suturing was done with 8-0 vicryl suture.

Both A and B group: Subconjuctival injection of gentamycin $0.3 \mathrm{ml}$ and dexamethasone $0.3 \mathrm{ml}$ were given. Moxifloxacin $0.5 \% \%$ eye drop and Predacetate $1 \%$ eye drop were advised to put 6 times par day and later on tapered. All the patients were examined post operatively on day 1 , day 7 , and then 1 month, 3 month and 6 month. On every visit unaided visual acuity and with pin hole visual acuity was recorded. Every patient was 


\section{JMSCR Vol||05||Issue||11||Page 31019-31022||November}

examined under slit lamp, for presence and absence of any complications.

\section{Observation and Results}

Table 1: Distribution of patients, according to age and sex

\begin{tabular}{|l|c|c|}
\hline Age in Years & Male & Female \\
\hline $40-49$ & 0 & 1 \\
\hline $50-59$ & 3 & 3 \\
\hline $60-69$ & 8 & 7 \\
\hline 70 and above & 10 & 4 \\
\hline Total & 21 & 15 \\
\hline
\end{tabular}

Total 36 eyes of 36 patients were included in this prospective study and they all had completed follow up for six months. They were divided into two groups group A - AC IOL and group B - SF IOL. The mean age of patients was 65.14 years and male to female ratio was $1.4: 1$.

Table 2 : Causes for Implantation of $\mathrm{AC}$ and $\mathrm{SF}$ IOL

\begin{tabular}{|l|c|c|}
\hline Cause & $\begin{array}{c}\text { Group A }- \text { AC } \\
\text { IOL }\end{array}$ & $\begin{array}{c}\text { Group B }- \text { SF } \\
\text { IOL }\end{array}$ \\
\hline $\begin{array}{l}\text { PC Rent following } \\
\text { IMSC surgery }\end{array}$ & 2 & 4 \\
\hline $\begin{array}{l}\text { PC Rent following } \\
\text { MSC sugery }\end{array}$ & 7 & 4 \\
\hline Old Aphakia patients & 4 & 5 \\
\hline Subluxated Cataract & 3 & 4 \\
\hline Traumatic Cataract & 2 & 1 \\
\hline
\end{tabular}

Posterior Capsule Rent, IMSC - Immature Senile cataract, MSC - Mature Senile cataract

Table 3 : Preoperative and postoperative after six months best corrected visual acuity (BCVA)

\begin{tabular}{|l|c|c|c|c|c|}
\hline VCVA & Groups & $\begin{array}{c}\text { Preoperative } \\
\mathrm{n}(\%)\end{array}$ & $\begin{array}{c}\text { Postoperative } \\
\text { after one month } \\
\mathrm{n}(\%)\end{array}$ & $\begin{array}{c}\text { Postoperative } \\
\text { after three month } \\
\mathrm{n}(\%)\end{array}$ & $\begin{array}{c}\text { Postoperative } \\
\text { after six month } \\
\mathrm{n}(\%)\end{array}$ \\
\hline $6 / 6-6 / 9$ & Group A (n=18) & $5(27.7)$ & $6(33.34)$ & $9(50)$ & $10(55.56)$ \\
\hline & Group B $(\mathrm{n}=18)$ & $5(27.7)$ & $7(38.89)$ & $9(50)$ & $11(61.11)$ \\
\hline $6 / 12-6 / 18$ & Group A (n=18) & $9(50)$ & $9(50)$ & $6(33.33)$ & 6 \\
\hline & Group B (n=18) & $10(55.5)$ & $10(55.56)$ & $7(38.89)$ & 5 \\
\hline $6 / 60$ and worse & Group A(n=18) & $4(22.2)$ & $3(16.67)$ & $3(16.67)$ & $2(11.11)$ \\
\hline & Group B (n=18) & $3(16.7)$ & $1(5.56)$ & $2(11.11)$ & $2(11.11)$ \\
\hline
\end{tabular}

Preoperative and postoperative vision assessment was done. BCVA 6/6-6/9 in $27.7 \%$ preoperatively months while in group B - SFIOL it improved improved to $55.56 \%$ in group A- ACIOL after six from $27.7 \%$ to $61.11 \%$ as shown in table.

Table 4 : Post operative complications in both groups

\begin{tabular}{|l|c|c|}
\hline Complications & $\begin{array}{c}\text { Group A AC IOL } \\
(\mathrm{n}=18)(\%)\end{array}$ & $\begin{array}{c}\text { Group A SF IOL } \\
(\mathrm{n}=18)\end{array}$ \\
\hline Mean Asigmatism & $1.25 \mathrm{D}$ & $2.4 \mathrm{D}$ \\
\hline AC Reaction(Iritis/Uveitis) & $4(22.22 \%)$ & $1(5.56 \%)$ \\
\hline Cystoid Macular Oedema & $2(11.1 \%)$ & $1(5.56 \%)$ \\
\hline Hyphema & 0 & 0 \\
\hline Hypotony & $1(5.56 \%)$ & 0 \\
\hline IOL Decentration & 0 & $2(11 \%)$ \\
\hline Stitch Granuloma & $1(5.55 \%)$ & 0 \\
\hline
\end{tabular}

Complication rate was analyzed in both the group and as shown in table 4 , the complication rate was higher in group A - ACIOL as compared to group B - SF IOL but IOL decentration was seen in group B only.

\section{Discussion}

In our study total 36 patients were included out of which 21 were males and 15 were females. The

male to female ratio is $1.4: 1$. The mean age was 66.14. All patients were operated by single surgeon to avoid any surgical variability which can give any variable results. All the patients were followed up for 6 months. BCVA $6 / 6-6 / 9$ in $27.7 \%$ preoperatively improved to $55.56 \%$ in group A - ACIOL after six months while in group B - SFIOL it improved from $27.7 \%$ to 
$61.11 \%$ as shown in table which is slightly higher in group B - SFIOL. While in study done by by Mushtaq Ahmad et al study ${ }^{1,}$ there was no statistically significant difference between final visual outcomes of two groups after six months. BCVA $6 / 6-6 / 9$ in $25 \%$ preoperatively improved to $56.25 \%$ in $\mathrm{AC}-\mathrm{IOL}$ and in SF-IOL, it improved from $31.25 \%$ to $56 \%$. Our results were also comparable to Ellakwa et $\mathrm{al}^{2}$ who showed no significant difference existed regarding the final visual outcome between anterior chamber and scleral fixation IOL groups. Donald et $\mathrm{al}^{3}$ suggested that there is no significant difference in outcome exist when comparing AC IOL to sutured PC IOL in complicated cataract extraction with poor capsular support. In Agarwal Amar ${ }^{4}$ study, post operative visual acuity was slightly higher in SF-IOL group as compared to AC - IOL and early post operative complication within 1 month occurred in $69.7 \%$ in the primary AC IOL group and $39.7 \%$ in secondary SFIOL group which favors our study. In our study uveits (22.22\%) was common complication in AC IOL group while cystoids macular oedema was $11.11 \%$ in AC-IOL group and $5.56 \%$ in SF-IOL group. Scleral fixation with sutures may cause more tilting of IOL as compared to AC IOL and PC IOL and this tilting has effect on postoperative astigmatism. The mean astigmatism is $2.5 \mathrm{D}$ in SFIOL group in our study and this may be due to tilting of intra ocular lens and large incision. Tommy C.Y. Chan ${ }^{5}$ study shows that there are no long term differences in the visual outcomes and complication profiles after primary ACIOL or secondary sclera fixated IOL implantation in a complicated cataract operation when capsular support is inadequate.

\section{Conclusion}

In our study we found that the best corrected visual acuity was slightly higher and complication rate was lower in SF-IOL implantation group than AC-IOL implantation group. Whatever is the cause of aphakia, proper preoperative evaluation, good intra operative vitrectomy followed by SF
IOL implantation give good postoperative comfort and better alternative to ACIOL. However, further large scale and long term evaluation is needed.

Conflict of Interest: is nil.

Source of Funding: The study was carried in Rama Medical College, Hapur and no extra financial support was required.

Ethical Clearance: Ethics committee approval was obtained before study.

\section{Bibliography}

1. Mushtaq Ahmad, Muhammad Naeem, Sofia Iqbal, Sanaullah Khan. Visual outcomes and complications of Anterior chamber Intra ocular lens versus Sclera fixated Intra ocular lens. Pak J Ophthalmol 2012, Vol. 28 No. 4

2. Ellakwa AF, Hegazy KA, Farahat HG, et al. Anterior chamber intraocular lens versus scleral fixated intraocular lens in cases with insufficient capsular support. MMJ July 2010; 23 :5- 12

3. Donaldson KE, Gorscak JJ, BudenzDL. Anterior chamber and sutured posterior chamber intraocular lenses in eyes with poor capsular support. J Cataract Refract Surg. 2005; 31: 03-9.

4. Anterior chamber, ScleraL fixated IOLs yield similar long term, Am.J. ophthalmol.2014;doi:10.1016/j.ajo.2014.1 0.16

5. Tommy C.Y. Chan, Jasamine K.M. Lam, Vishal Jhanji, Emmy Y.M., Comparison of outcomes of Primary anterior chamber versus secondary sclera fixated intra ocular lens implantation in complicated cataract surgeries. American Journal of Ophthalmology, February 2015, Vol. 159,Issue 2, Pages 221-226.e2. 